\title{
FABRICATION OF SMOOTH GaN-BASED LASER FACETS
}

\author{
D. A. Stocker, * E. F. Schubert, $*$ K. S. Boutros, ** J. M. Redwing** \\ *Center for Photonics Research, Boston University, Boston, MA 02215 \\ **Epitronics, Phoenix, AZ 85027
}

Cite this article as: MRS Internet J. Nitride Semicond. Res. 4S1, G7.5 (1999)

\begin{abstract}
A method is presented for fabricating fully wet-etched InGaN/GaN laser cavities using photoenhanced electrochemical wet etching followed by crystallographic wet etching. Crystallographic wet chemical etching of n- and p-type GaN grown on c-plane sapphire is achieved using $\mathrm{H}_{3} \mathrm{PO}_{4}$ and various hydroxides, with etch rates as high as $3.2 \mu \mathrm{m} / \mathrm{min}$. The crystallographic GaN etch planes are $\{0001\},\{10 \overline{1} 0\},\{10 \overline{1} \overline{1}\},\{10 \overline{1} \overline{2}\}$, and $\{10 \overline{1} 3\}$. The vertical $\{10 \overline{1} 0\}$ planes appear perfectly smooth when viewed with a field-effect scanning electron microscope (FESEM), indicating a surface roughness less than $5 \mathrm{~nm}$, suitable for laser facets. The etch rate and crystallographic nature for the various etching solutions are independent of conductivity, as shown by seamless etching of a p-GaN/undoped, high-resistivity GaN homojunction.
\end{abstract}

\section{INTRODUCTION}

Most post-growth processing of the III-nitrides is currently done by dry plasma etching. ${ }^{1,2}$ There are several disadvantages to dry etching, including the generation of ion-induced damage ${ }^{3}$ and difficulty in obtaining smooth etched sidewalls, which are required for lasers. The typical root-mean-square (RMS) roughness of sidewalls produced by dry etching is on the order of $50 \mathrm{~nm},{ }^{4,5}$ although recently surfaces with an RMS roughness as low as 4-6 nm have been reported. ${ }^{6}$ Photoenhanced electro-chemical (PEC) wet etching has also been demonstrated for etching of GaN. ${ }^{7-10}$ PEC etching has the advantage of low surface damage and low equipment cost, but a method for producing smooth vertical sidewalls by this method has not yet been found. Recently, a two-step process including crystallographic wet chemical etching has been demonstrated for n-type GaN. ${ }^{11}$ This process involves one conventional etching step, such as dry etching or PEC etching, followed by a second, crystallographic wet etching step. The two-step process provides smooth surfaces and can be used to create undercut, overcut, or vertical sidewalls.

\section{EXPERIMENT}

The first of the two etching steps in the crystallographic etching process is used to establish the etching depth, and it can be performed by several common processing methods, including dry etching, PEC etching, and cleaving. This first step is required because the c-plane $\{0001\}$ is impervious to all chemical agents investigated, ${ }^{12,13}$ except at defect sites where etch pits occur. ${ }^{14,15}$ In the second step the semiconductor sample is immersed in a hot chemical etchant that is able to crystallographically etch GaN. This etching step can produce smooth crystallographic surfaces, and the resulting etching planes are controlled by varying the orientation of the first step and the chemical agents and temperature of the second step. The etch 
rates and crystal planes observed for all chemicals used in this work are summarized in Table I. The etching planes listed in this table are those that appear during the etch.

In all cases the etch rate in the "vertical" [0001] direction is immeasurably small, but etching occurs "horizontally," i.e., normal to [0001]. Because the c-plane is impervious to all of the chemicals used in this study, no etch mask is required for the crystallographic etching step; the c-plane itself acts as a mask. An etch mask may be necessary, however, if long etching times are used, to prevent the development of etch pits at defect sites. For this purpose we have successfully used both titanium masks annealed at $900^{\circ} \mathrm{C}$ for 30 seconds in a nitrogen atmosphere and nickel masks annealed at $650^{\circ} \mathrm{C}$ for 2 minutes in a nitrogen atmosphere.

\section{RESULTS}

The $\{10 \overline{1} 0\}$ plane shown in Fig. 1 was produced by etching in $10 \% \mathrm{KOH}$ by weight dissolved in ethylene glycol at $170^{\circ} \mathrm{C}$. This plane has been examined using a high resolution field-effect scanning electron microscope (FESEM) with a resolution of $5 \mathrm{~nm}$ at $2.5 \mathrm{kV}$, and the surface appears perfectly smooth. This indicates that wet chemical etching may be a valuable tool for producing high-quality laser facets with reflectivities close to the ideal for a perfectly smooth surface. ${ }^{16}$

For this etching method to be useful for fabricating pn-junction laser diodes, the dependence of etch rate and surface morphology on doping must be determined. A scanning electron microscope (SEM) image of p-type GaN after anisotropic wet etching in molten $\mathrm{KOH}$ at a temperature of $195^{\circ} \mathrm{C}$ is shown in Fig. 2. Only the top portion of the epilayer is doped p-type; the lower $1 \mu \mathrm{m}$ is undoped. The seamless morphology of the surface displayed in Fig. 2 indicates that the change in doping does not affect the etch plane or the etch rate. The quality of the crystallographically etched surfaces is generally lower in the p-type material than in

Table I: Etch rates and observed etching planes for various chemicals

\begin{tabular}{|c|c|c|c|}
\hline Chemical & $\begin{array}{c}\text { Temperature } \\
\left({ }^{\circ} \mathrm{C}\right)\end{array}$ & $\begin{array}{l}\text { Etch Rate } \\
(\mu \mathbf{m} / \mathbf{m i n})\end{array}$ & $\begin{array}{l}\text { Etching Planes } \\
\text { Observed }\end{array}$ \\
\hline Acetic Acid $\left(\mathrm{CH}_{3} \mathrm{COOH}\right)$ & 30 & $<0.001$ & None \\
\hline Hydrochloric Acid ( $\mathrm{HCl})$ & 50 & $<0.001$ & None \\
\hline Nitric Acid $\left(\mathrm{HNO}_{3}\right)$ & 81 & $<0.001$ & None \\
\hline Phosphoric Acid $\left(\mathrm{H}_{3} \mathrm{PO}_{4}\right)$ & $108-195$ & $0.013-3.2$ & $\{10 \overline{1} \overline{2}\},\{10 \overline{1} 3\}$ \\
\hline Sulphuric Acid $\left(\mathrm{H}_{2} \mathrm{SO}_{4}\right)$ & 93 & $<0.001$ & None \\
\hline Potassium Hydroxide $(\mathrm{KOH})$, molten & $150-247$ & $0.003-2.3$ & $\{10 \overline{1} 0\},\{10 \overline{1} \overline{1}\}$ \\
\hline $50 \% \mathrm{KOH}$ in $\mathrm{H}_{2} \mathrm{O}$ & 83 & $<0.001$ & None \\
\hline $\begin{array}{l}10-50 \% \mathrm{KOH} \text { in Ethylene Glycol } \\
\left(\mathrm{CH}_{2} \mathrm{OHCH}_{2} \mathrm{OH}\right)\end{array}$ & $90-182$ & $0.0015-1.3$ & $\{10 \overline{1} 0\}$ \\
\hline $50 \% \mathrm{NaOH}$ in $\mathrm{H}_{2} \mathrm{O}$ & 100 & $<0.001$ & None \\
\hline $\begin{array}{l}\text { Tetramethylammonium Hydroxide } \\
\text { (TMAH) }\end{array}$ & 76 & 0.013 & $\{10 \overline{1} \overline{2}\}$ \\
\hline $\begin{array}{l}\text { Tetraethylammonium Hydroxide } \\
\text { (TEAH) }\end{array}$ & 91 & 0.007 & $\{10 \overline{1} \overline{2}\}$ \\
\hline $20 \% \mathrm{NaOH}$ in Ethylene Glycol & 178 & $0.67-1.0$ & None \\
\hline
\end{tabular}




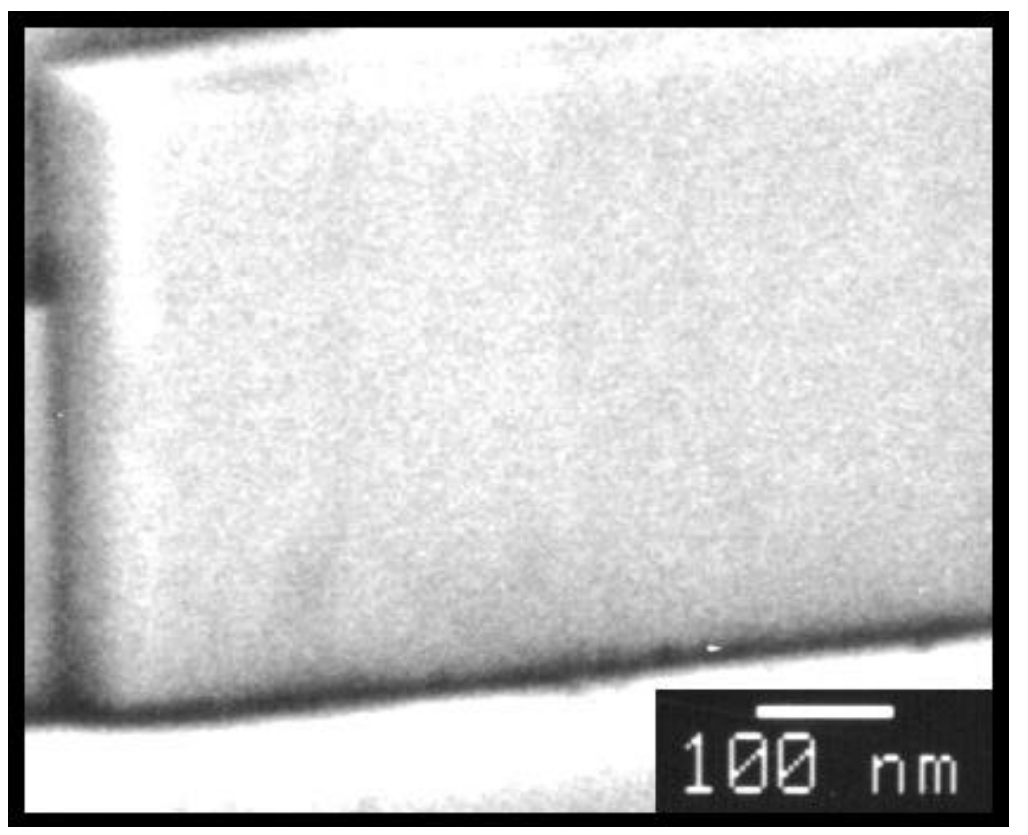

FIG. 1: High-resolution field-effect SEM image of a vertical $\{10 \overline{1} 0\}$ plane etched in $\mathrm{n}-\mathrm{GaN}$ by $\mathrm{KOH}$ dissolved in ethylene glycol at a temperature of $170^{\circ} \mathrm{C}$.

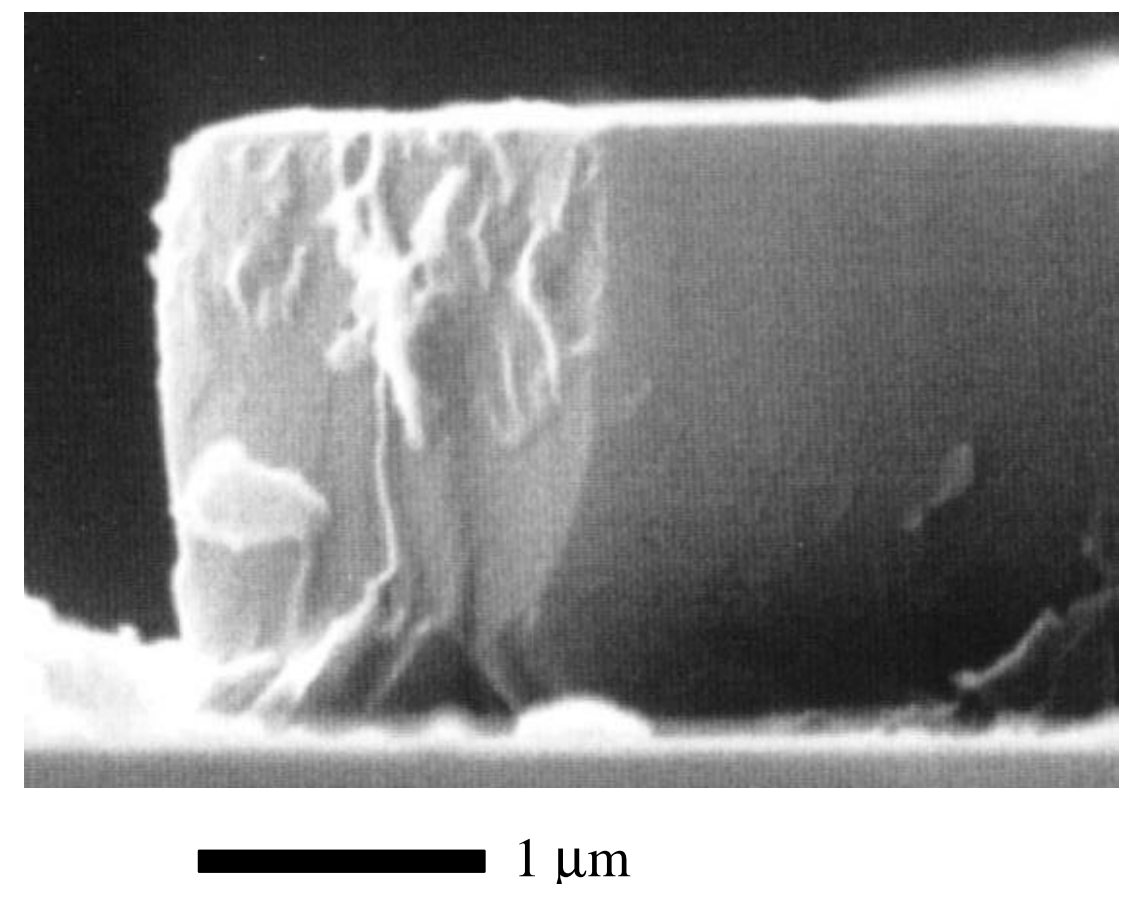

FIG. 2: SEM image of a $\{10 \overline{1} 0\}$ surface made by crystallographic wet etching in molten $\mathrm{KOH}$ at $195^{\circ} \mathrm{C}$. The upper portion of the epilayer is $\mathrm{p}-\mathrm{GaN}$, while the lower $1 \mu \mathrm{m}$ is highly resistive $\mathrm{GaN}$. 
the n-type material; in many cases, the only distinct crystal plane left after etching is the c-plane. The reason for this difference is unclear at the present time. It seems to be unrelated to crystal quality; the crystals are of similar quality, as indicated by x-ray rocking curve full-width-at-halfmaxima of $800-900$ arcsec and by etch pit densities on the order of $5 \times 10^{7} \mathrm{~cm}^{-2}$ after etching in molten $\mathrm{KOH}$. The difference is also not related to the doping, since the p-type material etches seamlessly with the undoped material on which it is grown.

We are currently using photoenhanced electrochemical (PEC) etching and crystallographic wet etching to fabricate fully wet-etched laser cavities in an InGaN:Si/GaN double heterostructure. The structure consists of an initial $10-\mu \mathrm{m}$-thick buffer layer of $\mathrm{GaN}$ grown on c-plane sapphire by HVPE, and a $0.5 \mu \mathrm{m}$ GaN bottom cladding layer, a $1000 \AA$ $\mathrm{In}_{0.09} \mathrm{Ga}_{0.91} \mathrm{~N}$ :Si active region, and a $2200 \AA$ GaN top cladding layer grown by MOVPE. This is the same structure which we have previously used to demonstrate optically pumped cleavedfacet lasers. ${ }^{17}$ Waveguide calculations reveal that the heterostructure is a single-mode waveguide with an active region confinement factor of $6 \%$. The guided mode is confined mainly to the upper portion of the epilayers, with $50 \%$ of the intensity carried in the top $2 \mu \mathrm{m}$.

180-nm-thick annealed Ni masks are used to define cavities with lengths varying from $50 \mu \mathrm{m}$ to $500 \mu \mathrm{m}$. The unusually thick Ni layer is used to minimize the light penetrating into the masked area during PEC etching. The edges of the masks are aligned with the $\langle 1120\rangle$ direction of the GaN, so that the resulting PEC-etched sidewalls correspond with the $\{1010\}$ plane for subsequent crystallographic etching.

The PEC etching is done under voltage biased conditions in a $0.03 \mathrm{M} \mathrm{KOH}$ solution at room temperature. During etching, the samples are clamped against a nickel bar and immersed along with a gold wire cathode in the aqueous $\mathrm{KOH}$ solution. Voltage and current are both monitored and a DC power supply is used to apply a bias voltage of $-2 \mathrm{~V}$ on the anode. The bias voltage has been found to improve the uniformity of the etching process, minimizing the roughness which is commonly seen when using PEC etching with $\mathrm{GaN}$. Ultraviolet illumination is provided by a $200 \mathrm{~W} \mathrm{Hg}$ lamp, and a silicon wafer is used as a cold mirror to reduce heating by increasing the ratio of UV to IR illumination. The time required to produce vertical sidewalls extending down to the sapphire substrate under these conditions is 4 hours. A typical PECetched sidewall in this material is shown in Fig. 3(a). The nickel mask is visible at the top of the image, and is allowed to remain in place throughout the subsequent crystallographic etching. As the image shows, the PEC-etched sidewall is extremely rough and has a fibrous texture, although the sapphire surface has etched cleanly. The clean sapphire surface shows the effectiveness of the bias voltage in eliminating the islands often formed on the sapphire substrate by uneven PEC etching of the GaN. Note that there are some deep holes in the top $1 \mu \mathrm{m}$ of the structure, near the InGaN layer. These holes form during PEC etching, but the etching mechanism is not yet understood.

The sidewall produced by PEC etching is far too rough to be used as a laser facet, since the reflectivity is strongly dependent upon surface roughness. ${ }^{16}$ Crystallographic etching in molten $\mathrm{KOH}$ is used to smooth the PEC-etched surface to improve the reflectivity. The series of SEM images in Fig. 3(b)-3(d) shows the effect of etching in $175^{\circ} \mathrm{C}$ molten $\mathrm{KOH}$ on the PECetched sidewall. The etch rate at this temperature is approximately $0.05 \mu \mathrm{m} / \mathrm{min}$. The fibrous PEC-etched surface shows considerable smoothing after only 1 minute of crystallographic etching, as can be seen in Fig. 3(b). Further improvement is observed in Fig. 3(c) after three minutes of crystallographic etching. After five minutes of etching, no further smoothing occurs; the image shown in Fig. 3(d) after nine minutes of etching is very similar to images taken 

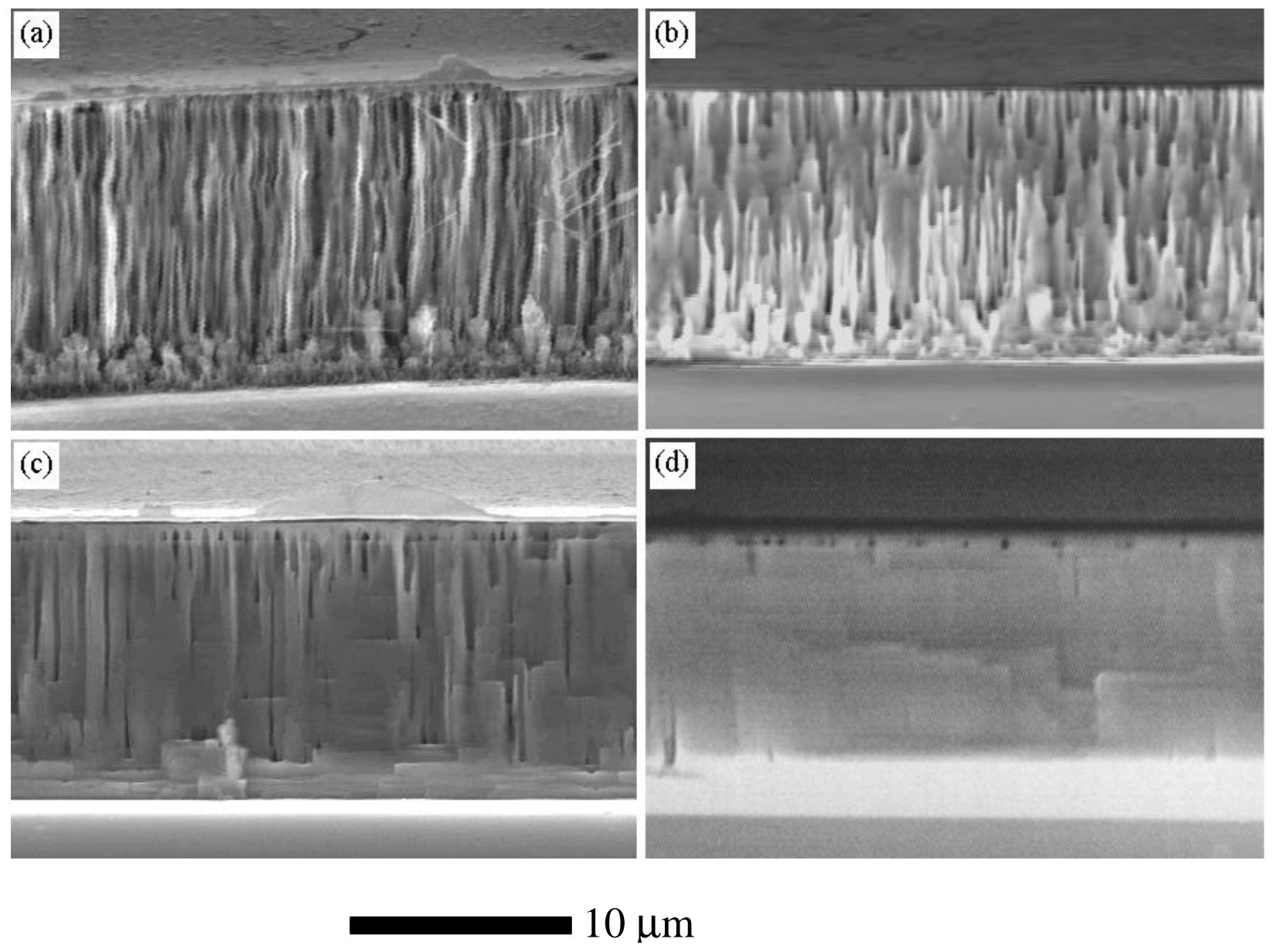

FIG. 3: Smoothing of a surface produced by photo-enhanced electrochemical (PEC) etching of an InGaN/GaN double heterostructure. The $10 \mu \mathrm{m}$ bar underneath the figure is valid for all of the SEM images. (a) PEC-etched surface before smoothing by crystallographic etching in molten $\mathrm{KOH}$ at $175^{\circ} \mathrm{C}$. (b) PEC-etched surface after smoothing for $1 \mathrm{~min}$. (c) After smoothing for 3 min. (d) After smoothing for 9 min.

anywhere in the range of five to ten minutes. Note that the density of holes in the top $1 \mu \mathrm{m}$ does not tend to change during crystallographic etching. Horizontal steps like those across the center of Fig. 3(d) are common features produced by crystallographic etching in $\mathrm{KOH}$. These may be due to anisotropy of etch rate in the [0001] and [0001] directions.

The usefulness of these wet-etched sidewalls for laser facets is currently under investigation. We believe that the horizontal steps will not have a significant effect on the reflectivity, since the waveguide confines the guided mode mostly in the upper part of the epilayers.

\section{CONCLUSIONS}

We have presented a method for fabricating fully wet-etched laser facets for GaN-based laser structures. Photoenhanced electrochemical (PEC) etching is used to produce rough vertical facets which are aligned with the $\{10 \overline{1} 0\}$ planes of the GaN. Crystallographic wet chemical etching is used to smooth the rough PEC-etched surfaces. The resulting facets have large areas where the roughness is less than $5 \mathrm{~nm}$, the smoothest etched vertical sidewalls which have been 
reported to date. The crystallographic etching used to produce the vertical $\{10 \overline{1} 0\}$ facets is independent of carrier concentration, which suggests its usefulness in fabricating wet-etched laser diodes.

\section{REFERENCES}

${ }^{1}$ J. C. Zolper and R. J. Shul, MRS Bulletin 22 (2), 36 (1997).

${ }^{2}$ H. P. Gillis D. A. Choutov, and K. P. Martin, JOM 48 (8), 50 (1996).

${ }^{3}$ F. Ren, J. R. Lothian, S. J. Pearton, C. R. Abernathy, C. B. Vartuli, J. D. MacKenzie, R. G. Wilson, and R.F. Karlicek, Journal of Electronic Materials 26, 1287 (1997).

${ }^{4}$ S. Nakamura, M. Senoh, S. Nagahama, N. Iwasa, T. Yamada, T. Matsushita, H. Kiyoku, Y. Sugimoto, Jpn. J. Appl. Phys. 35, L74 (1996).

${ }^{5}$ F. Binet, J. Y. Duboz, N. Laurent, C. Bonnat, P. Collot, F. Hanauer, O. Briot, R. L. Aulombard, Appl. Phys. Lett. 72, 960 (1998).

${ }^{6}$ M. Kneissl, D. P. Bour, N. M. Johnson, L. T. Romano, B. S. Krusor, R. Donaldson, J. Walker, C. Dunnrowicz, Appl. Phys. Lett. 72, 1539 (1998).

${ }^{7}$ M.S. Minsky, M. White, and E.L. Hu, Appl. Phys. Lett. 68, 1531 (1996).

${ }^{8}$ L.-H. Peng, C.-W. Chuang, J.-K. Ho, C.-N. Huang, and C.-Y. Chen, Appl. Phys. Lett. 72, 939 (1998).

${ }^{9}$ H. Lu, Z. Wu, and I. Bhat, J. Electrochem. Soc. 144, L8 (1997).

${ }^{10}$ C. Youtsey, I. Adesida, L. T. Romano, and G. Bulman, Appl. Phys. Lett. 72, 560 (1998).

${ }^{11}$ D. A. Stocker, E. F. Schubert, and J. M. Redwing, Appl. Phys. Lett. 73, 2654 (1998).

${ }^{12}$ M. Seelmann-Eggebert, J. L. Weyher, H. Obloh, H. Zimmermann, A. Rar, and S. Porowski, Appl. Phys. Lett. 71, 2635 (1997).

${ }^{13}$ C. B. Vartuli, S. J. Pearton, C. R. Abernathy, J. D. MacKenzie, F. Ren, J. C. Zolper, and R. J. Shul, Solid-State Electronics 41, 1947 (1997).

${ }^{14}$ A. Shintani and S. Minagawa, J. Electrochem. Soc. 123, 706 (1976).

${ }^{15}$ T. Kozawa, T. Kachi, T. Ohwaki, Y. Taga, N. Koide, M. Koike, J. Electrochem. Soc. 143, L17 (1996).

${ }^{16}$ D. A. Stocker, E. F. Schubert, W. Grieshaber, K. S. Boutros, and J. M. Redwing, Appl. Phys. Lett. 73, 1925 (1998).

${ }^{17}$ D. A. Stocker, E. F. Schubert, K. S. Boutros, J. S. Flynn, R. P. Vaudo, V. M. Phanse, and J. M. Redwing, Electron. Lett. 34, 373 (1998). 